\title{
Granulovacuolar Degeneration Bodies of Alzheimer's Disease Resemble Late-stage Autophagic Organelles
}

\author{
Kristen E. Funk ${ }^{\star}$, Robert E. Mrak $^{\dagger}$, and Jeff Kuret ${ }^{\star}$ \\ "Department of Molecular and Cellular Biochemistry, Center for Molecular Neurobiology, The \\ Ohio State University, Columbus, $\mathrm{OH}$ \\ tDepartment of Pathology, University of Toledo College of Medicine, Toledo, $\mathrm{OH}$
}

\section{Abstract}

\begin{abstract}
Aims-Granulovacuolar degeneration involves the accumulation of large, double membranebound bodies within certain neurons during the course of Alzheimer's disease and other adultonset dementias. Because of the two-layer membrane morphology, it has been proposed that the bodies are related to autophagic organelles. The aim of this study was to test this hypothesis, and determine the approximate stage at which the pathway stalled in Alzheimer's disease.
\end{abstract}

Methods-Spatial colocalization of autophagic and endocytic markers with casein kinase 1 delta, a marker for GVD bodies, was evaluated in hippocampal sections prepared from postmortem Braak stage IV and V Alzheimer's disease cases using double-label confocal fluorescence microscopy.

Results-GVD bodies colocalized weakly with early-stage autophagy markers LC3 and p62, but strongly with late-stage marker LAMP1 (lysosome-associated membrane protein 1), which decorated their surrounding membranes. GVD bodies also colocalized strongly with CHMP2B (charged multivesicular body protein $2 \mathrm{~B}$ ), which colocalized with the core granule, but less strongly with lysosomal marker cathepsin D.

Conclusions-The resultant immunohistochemical signature suggests that GVD bodies contain late-stage autophagic markers, and accumulate at the nexus of autophagic and endocytic pathways. . The data further suggest that failure to complete autolysosome formation may be an important correlate of GVD body accumulation.

\section{Keywords}

Alzheimer's disease; granulovacuolar degeneration; autophagy; endocytosis; lysosome

\section{Introduction}

Granulovacuolar degeneration (GVD) is characterized by the intraneuronal accumulation of large (up to $5 \mu \mathrm{m}$ diameter) membrane-bound vacuoles harbouring a central granule. Although originally observed in Alzheimer's disease (AD) [1], and classically detected in hippocampal pyramidal neurons [2], GVD also affects additional brain regions [3,4] and is found above age-matched control levels in other adult-onset dementias including forms of frontotemporal lobar degeneration [5]. In AD hippocampus, granulovacuolar degeneration

Correspondence: Jeff Kuret, PhD., Center for Molecular Neurobiology, 1060 Carmack Rd., Columbus, OH 43210. Tel: +1 614688 5899; Fax: +1 614292 5379; kuret.3@osu.edu.

Author declaration: None of the authors listed above has declared any conflict of interest within the last three years which may arise from being named as an author on this manuscript. 
body (GVB) load increases with disease severity in parallel with neurofibrillary lesion density [6,7] and correlates strongly with decline of episodic memory performance [8]. Much like the defining lesions of AD, $\beta$-amyloid plaques and neurofibrillary tangles, GVBs have a well-documented but poorly understood connection to disease progression. Elucidation of GVB composition and origin may offer additional insight into the pathogenesis of sporadic disease.

Toward that end, GVB ultrastructure has been extensively studied, revealing a central electron-dense granule with coarse or vesicular morphology and a surrounding double unit membrane [9]. On the basis of the latter characteristic, a macroautophagic origin for GVBs has been proposed [9]. Macroautophagy (hereafter referred to as autophagy) begins with the formation and extension of an isolation membrane, or phagophore, that is double-layered and decorated by the autophagic membrane protein LC3 (microtubule-associated protein 1 light chain 3; Figure 1) [10-12]. Upon closure of the membrane, the resultant autophagosome undergoes a stepwise maturation process involving fusion with late endosomes/multivesicular bodies to form amphisomes, and finally with lysosomes to yield autolysosomes (Figure 1). The latter maturation steps acquire ATPases that acidify the vacuolar lumen, and lysosomal hydrolases such as cathepsins that degrade the inner autophagic membrane and its sequestered cargoes [13,14]. Digested materials are then transported back to the cytoplasm and recycled [15]. Because autophagy is a dynamic and efficient process in healthy neurons, autophagic intermediates are rarely observed unless their formation or clearance is inhibited [16]. Whether autophagic misfunction contributes to GVB formation is unknown.

Autophagic vesicles can sequester ubiquitinated substrates in cytoplasm, including those that form protein aggregates [17]. Consistent with this potential function, GVB granules contain ubiquitin immunoreactivity $[9,18]$. On the other hand, neurons undergoing GVD only modestly overlap with those containing tau aggregates [19,20], and GVB granules contain only weak phospho-tau immunoreactivity [21-24]. Moreover, neither induction nor inhibition of autophagy alone has been reported to yield GVBs in model systems [16]. Autophagy is but one process through which cellular constituents enter lysosomes for degradation (Figure 1), and more than one pathway may contribute to the formation of GVBs.

Traditionally, GVD has been detected with non-specific histological stains such haematoxylin and eosin, which has slowed progress in characterizing the molecular composition of GVBs. However, we reported that $\mathrm{Cki} \delta$, a protein kinase implicated in protein ubiquitination, is a robust surrogate marker for the GVB granule [25]. Through this approach it is now possible to conduct GVB colocalization experiments in authentic AD tissue. Here we use immunohistochemistry to probe the relationship between GVBs and representative proteins associated with the autophagic and endocytotic processes. The results show that GVBs contain autophagic and endocytic markers, and have an epitope signature most consistent with the amphisome stage of autophagy. The results point to incomplete lysosome fusion as a potentially important correlate of GVB formation.

\section{Materials and methods}

\section{Subjects}

This study utilized only archival, anonymised postmortem brain tissue samples from autopsies performed with informed consent of each patient or relative via procedures approved by the relevant institutional committees (University of Toledo; Case Western Reserve University). Samples included tissue from five elderly subjects with a clinical diagnosis of $\mathrm{AD}$ (mean age $71 \pm 11$ years (SD); Table 1) that was confirmed on 
neuropathological evaluation in which the Consortium to Establish a Registry for AD

(CERAD) age-adjusted criteria were met [26]. All cases satisfied criteria for Braak stages IV or V [27].

\section{Tissue preparation and Immunohistochemistry}

Hippocampal brain tissue obtained postmortem was fixed in either methacarn (methanol:chloroform:acetic acid; 6:3:1) or phosphate-buffered 20\% formalin (8\% formaldehyde), embedded in paraffin, and sliced into 6- $\mu \mathrm{m}$ thick sections. Tissue sections were then deparaffinized in xylene, rehydrated in a descending series of ethanol concentrations, then subjected to antigen retrieval (low microwave heating for $20 \mathrm{~min}$; [28]) in citrate buffer ( $10 \mathrm{mM}$ citric acid, $0.5 \%$ Tween-20, $\mathrm{pH} 6.0)$ followed by washing $(2 \times 5$ min) in PBST ( $2.7 \mathrm{mM} \mathrm{KCl}, 0.14 \mathrm{M} \mathrm{NaCl}, 8.1 \mathrm{mM} \mathrm{Na}_{2} \mathrm{HPO}_{4}, 0.1 \%$ Tween-20, $\mathrm{pH}$ 7.4). Washed sections were then blocked $\left(1 \mathrm{~h}\right.$ at $\left.19^{\circ} \mathrm{C}\right)$ with $5 \%$ goat serum diluted in phosphate buffer (PB; $33 \mathrm{mM} \mathrm{NaH} \mathrm{PO}_{4}, 162 \mathrm{mM} \mathrm{Na}_{2} \mathrm{HPO}_{4}, \mathrm{pH} 7.4$ ), then incubated (overnight at $4^{\circ} \mathrm{C}$ ) with primary antibodies (Table 2) diluted in $\mathrm{PB}$ containing $2.5 \%$ goat serum. After washing in PBST $(3 \times 10 \mathrm{~min})$, sections were incubated $\left(1 \mathrm{~h}\right.$ at $\left.19^{\circ} \mathrm{C}\right)$ with fluorescent dyelabeled secondary antibodies $(1.5 \mu \mathrm{g} / \mathrm{ml} \mathrm{Cy} 3$-conjugated goat anti-rabbit IgG, Jackson Immuno Research Laboratories, Inc, West Grove, PA; $2 \mu \mathrm{g} / \mathrm{ml}$ Alexa Fluor 488-conjugated goat anti-mouse IgG, Invitrogen, CA). After washing in PBST ( $3 \times 10 \mathrm{~min})$, tissue was treated $\left(10 \mathrm{~min}\right.$ at $\left.19^{\circ} \mathrm{C}\right)$ with $0.1 \%$ Sudan Black B (EM Diagnostics, Gibbstown, NJ) in $80 \%$ ethanol to suppress lipofuscin autofluorescence [29]. Sections were then washed $(2 \times$ $10 \mathrm{~min}$ ) in PBST and once for $10 \mathrm{~min}$ in PB. Coverslips were mounted with Vectashield (Vector Laboratories, Burlingame, $\mathrm{CA}$ ) and sealed with clear nail enamel. Labeled sections were viewed in a Leica TCS SL laser-scanning confocal system (100x oil HCX Plan Apo CS $0.70-1.40$ NA objective lens) operated at wavelengths optimized for simultaneous detection of Alexa Fluor $488\left(\lambda_{\mathrm{ex}}=488 \mathrm{~nm} ; \lambda_{\mathrm{em}}=500-530 \mathrm{~nm}\right)$ and $\mathrm{Cy} 3\left(\lambda_{\mathrm{ex}}=543 \mathrm{~nm}\right.$; $\left.\lambda_{\mathrm{em}}=560-600 \mathrm{~nm}\right)$. Long-wavelength fluorescence $\left(\lambda_{\mathrm{ex}}=633 \mathrm{~nm} ; \lambda_{\mathrm{em}}=650-740 \mathrm{~nm}\right)$ also was monitored to assess autofluorescence intensity. Digital confocal images were captured at $1 \mathrm{x}$ and $4 \mathrm{x}$ digital zoom, and stored in Tagged Image Format. Both secondary antibodies displayed minimal non-specific staining under these conditions as determined by immunostaining in the absence of primary antibodies.

\section{Assessment of colocalization of GVD with autophagy markers}

To assess the relationship between autophagy and GVD in AD hippocampus (Braak stages IV and V, Table 1), the distribution of various marker proteins (Table 2) was compared to that of GVBs (marked by Ckiס) using double-label confocal immunofluorescence microscopy. Colocalization was assessed both at the cellular and subcellular levels, and was limited to only those GVBs having a diameter of at least $1 \mu \mathrm{m}$ to facilitate quantification. At the subcellular level, colocalization was defined as "granular" when marker immunoreactivity directly overlapped Cki $\delta$ immunoreactivity in a GVB granule, and as "encircling" when it surrounded the periphery of a GVB vacuole. At the cellular level, colocalization was defined as the presence of at least one example of the encircling or granular patterns in a neuron undergoing GVD. The two types of subcellular colocalization, encircling and granular, were pooled from multiple observations from each case (technical replicates) and quantified as the mean percent colocalization.

\section{Analytical evaluation of immunohistochemical staining and statistics}

The proportion of Cki $\delta$-immunoreactive GVBs that colocalized with each marker was analyzed using the Wilson score method [30]. At least 60 technical replicates were counted from at least 10 fields of each case so that the $95 \%$ confidence interval for colocalization was $\leq 15 \%$. Overall mean colocalization (for both cellular and subcellular observations) was then calculated as the average of all five biological replicate means and reported \pm standard 
error of the mean. Analysis was conducted at both the cellular (colocalization with neurons undergoing GVD) and subcellular (colocalization with individual GVBs) levels.

Differences in colocalization of markers with GVBs were assessed by $z$-test:

$$
z=\frac{x_{1}-x_{2}}{\sqrt{\left(S_{x 1}\right)^{2}+\left(S_{x 2}\right)^{2}}}
$$

where $\mathrm{x}_{1} \pm S_{\mathrm{x} 1}$ and $\mathrm{x}_{2} \pm S_{\mathrm{x} 2}$ are the pair of overall mean colocalization estimates \pm SE being compared, $z$ is the 1- $\alpha$ point of the standard normal distribution, and $p$ (the probability of obtaining the observed results assuming the null hypothesis) is $2 \alpha$. All statistical analyses were carried out using JMP 8 (SAS Institute, Cary, NC).

\section{Results}

\section{Colocalization with early-stage autophagy markers}

The colocalization of GVBs with early-stage autophagy markers was probed with antibodies raised against LC3 and p62 (Table 2). The lipidated form of LC3 (LC3-II) is bound by both the inner and outer membrane of the autophagosome, and thus colocalizes with the earliest stages of autophagosome formation (Figure 1) [11,31]. LC3-II decreases with autophagosome maturation, however, owing to partial proteolysis and delipidation of the outer-membrane by cysteine protease Atg4 [32] and destruction of the inner membrane by lysosomal/endosomal hydrolases. Therefore, LC3 primarily marks the phagophore and autophagosome relative to late-stage compartments (i.e., the amphisome and the autolysosome). When AD hippocampus was investigated by double-label immunofluorescence microscopy, Ckiס immunoreactivity displayed the punctate cytoplasmic pattern previously shown to correspond to GVBs (Figure 2a,d) [25]. In contrast, LC3 immunoreactivity was typically diffuse and filled neuronal cell bodies (Figure 2b,e) in agreement with a previous report [33]. However, the diffuse LC3 staining pattern colocalized only weakly with GVBs at the cellular or subcellular levels (Figure 2c, f; Figure 3 ), suggesting that GVBs do not correspond to early-stage autophagy organelles.

To confirm this finding, the distribution of p62 was investigated. p62 binds ubiquitin, and is commonly found associated with polyubiquitinated protein aggregates including those in neurofibrillary tangles [34-36]. It also binds LC3, and so can act as an adaptor protein to facilitate autophagic degradation of ubiquitinated substrates [37]. Thus, p62 immunoreactivity predominates in cells containing ubiquitinated protein aggregates and accumulates in non-degradative autophagic compartments (phagophore and autophagosome) relative to amphisomes and autolysosomes where it is destroyed. Double-label immunofluorescence microscopy confirmed that p62 colocalized with neurofibrillary tangles, however it rarely colocalized with GVBs at the cellular or subcellular levels (Figure $2 \mathrm{~g}-1$; Figure 3$)$. This low level of colocalization did not differ significantly $(p<0.05)$ from that observed for LC3 at the cellular or subcellular levels. Together, both LC3 and p62 immunostaining patterns suggest that GVBs do not resemble early-stage autophagy organelles.

\section{Colocalization with late-stage autophagy markers}

Late-stage autophagy was probed with markers LAMP1 (lysosome-associated membrane protein-1) and CTSD (cathepsin D). LAMP1 is a membrane glycoprotein associated with late endosome, amphisome, and lysosome organelles, and thus can distinguish the later stages of the autophagic pathway from earlier stages $[38,39]$. Double-label 
immunofluorescence microscopy revealed that LAMP1 immunoreactivity in AD hippocampal neurons undergoing GVD displayed a punctuate pattern throughout cytoplasm except in the immediate vicinity of GVBs, where it adopted an encircling colocalization pattern (Figure $4 \mathrm{a}-\mathrm{c}$ ). At the cellular level, $75 \pm 7 \%$ of neurons undergoing GVD contained encircling LAMP1 immunoreactivity (Figure 3), which was significantly higher than the colocalization found for either early-stage autophagy marker LC3 or p62 $(p<0.001)$. At the subcellular level, colocalization with GVBs averaged $32 \pm 7 \%$ (Figure 3), which again was significantly higher than the colocalization observed with LC3 or p62 $(p<0.001)$. These data are consistent with LAMP1 being a membrane protein associated with the surrounding membrane of the GVB vacuole. These data also indicate that GVBs are more closely related to late-stage than to early-stage autophagic organelles.

To extend this finding, the distribution of CTSD was investigated. CTSD is a major intracellular aspartic protease expressed in nearly all neurons and glial cells [40]. It reportedly associates with late-stage autophagic organelles and endosomes, but with highest levels in lysosomes. For example, lysosomal CTSD levels have been reported to be nearly an order of magnitude above levels in late endosomes [41,42]. Thus CTSD immunostaining was expected to be a sensitive probe for lysosomes and their fusion products. Double-label immunofluorescence microscopy revealed that CTSD immunoreactivity in AD hippocampal neurons undergoing GVD adopted a punctuate pattern throughout the cytoplasm with occasional granular colocalization with GVBs (Fig 4d-f). At the cellular level, $44 \pm 10 \%$ of neurons undergoing GVD contained CTSD immunoreactivity colocalizing with GVBs (Figure 3). Although this was significantly higher than the colocalization found for either early-stage autophagy marker LC3 or p62 $(p<0.001)$, it was significantly lower than for marker LAMP1 $(p<0.01)$. At the subcellular level, $13 \pm 4 \%$ of GVBs colocalized with CTSD (Figure 3), which again was significantly greater than the colocalization observed with LC3 or p62 $(p<0.01)$ but significantly lower than the value for LAMP1 $(p<0.05)$. Together with LAMP1 immunoreactivity, these data are consistent with GVBs being more closely related to late-stage than early-stage autophagic organelles. Because GVD granules are enveloped by LAMP1-containing membranes but contain limited amounts of CTSD, GVBs likely represent a vesicle similar to the amphisome in the autophagic pathway and point toward limited autolysosome formation as the approximate point of stalling.

\section{Colocalization with endocytic protein CHMP2B}

Amphisomes represent an intersection between endocytosis and autophagy, the two major pathways to the lysosome. Thus, under some circumstances, accumulation of amphisomes may be accompanied by endocytosis markers. A component of the endocytosis pathway, CHMP2B, has been reported to colocalize with GVBs at the cellular level [4]. CHMP2B is a component of the endosomal sorting complex required for transport-III (ESCRT-III), which is involved in endocytic trafficking of proteins $[43,44]$. ESCRT-III drives the formation and specifically the scission of intraluminal vesicles in MVBs, and under certain conditions remain associated with them [45]. Therefore, the distribution of CHMP2B in AD hippocampus was quantified. Double-label immunofluorescence microscopy revealed that CHMP2B immunoreactivity adopted a punctate pattern having strong granular colocalization with GVBs (Figure $4 \mathrm{~g}-1$ ). At the cellular level, $98 \pm 1 \%$ of neurons undergoing GVD contained granular overlapping CHMP2B immunoreactivity, which was significantly greater than the degree of colocalization found for any other investigated autophagy marker $(p<0.001)$. At the subcellular level, colocalization with GVBs averaged $82 \pm 3 \%$ (Figure 3 ), which again was significantly higher than the colocalization observed with the autophagy markers investigated above $(p<0.001)$. These data confirm that GVBs represent an organelle population with characteristics similar to amphisomes, but enriched with granular content from the endosomal pathway. 


\section{Discussion}

On the basis of their ultrastructural morphology, GVBs have been proposed to bear some relation to autophagic organelles [9]. Here we found that GVBs do indeed harbour autophagic marker proteins, especially those associated with the later stages of organelle maturation. Their epitope signature is consistent with organelles formed after fusion of autophagosomes with multivesicular bodies/late endosomes but before autolysosome maturation is complete. These data point to GVBs accumulating at the nexus between autophagy and endocytosis, the two major trafficking pathways to the lysosome in neurons. Thus, GVBs could potentially arise from increased or aberrant flux through one or both of these pathways combined with a failure of lysosome-mediated clearance.

Of these three general possibilities, upregulation of autophagic flux is especially attractive as a modulator of neuritic lesion formation in $\mathrm{AD}$. Indeed, various autophagy-derived bodies are reportedly capable of degrading protein aggregates [17], serving as a nidus for neuronal inclusion formation [46], and protecting against cell death [47]. Nonetheless, it is not clear that increased authophagic flux contributes to GVB formation. First, a key suppressor of autophagy induction, the mTOR protein kinase [48], is more heavily autophosphorylated at Ser2481 in AD relative to normal brain [49], consistent with its activation [50]. Under these conditions, initiation of phagophore formation is predicted to be suppressed rather than activated in AD relative to normal brain. Second, tau aggregates appear in the same neurons undergoing GVD [51], but rarely [19,20], and not within the GVB itself [9]. Moreover, phospho-tau epitopes have been discovered within GVBs [21-24], but the failure to detect many nonphospho-tau epitopes [18] raises the issue of non-specific binding. In fact, GVBs bind several anti-phospho-epitope antibodies raised against diverse proteins while paradoxically failing to display the corresponding non-phospho epitopes [52]. Third, p62, which could potentially facilitate autophagic clearance of ubiquitinated tau aggregates by tethering them to LC3 [37,53], only weakly colocalizes with GVBs despite its association with neurofibrillary tangles. Although a punctuate immunostaining pattern was reported for this protein in AD brain [52], the results herein suggest that this pattern is unrelated to GVD. Finally, induction of autophagy in neurons is insufficient by itself to drive the accumulation of intermediate organelles [16]. Together these observations suggest that GVBs form independently of neuritic lesions [54] and are unconstrained by limitations in autophagic flux.

Aberrant flux through the endocytic system also is attractive as a contributor to GVD, since this system is at least partially responsible for the increased processing of APP to $\beta$-amyloid peptide observed in AD [55]. As reported previously [4] and confirmed here, the endocytic system does appear to make a substantial contribution to the contents of GVBs, as indicated by strong colocalization of CHMP2B with the GVB granule. CHMP2B is a member of the ESCRT-III complex (Figure 1), which mediates membrane abscission during formation of the intraluminal vesicles within the multivesicular body [45,56]. It functions to recruit VPS4, an AAA+ ATPase required for the disassembly and recycling of ESCRT subunits [57]. When this function is diminished through truncation mutagenesis, CHMP2B accumulates within MVBs instead of recycling [45]. Because VPS4 activity is subject to regulation under normal conditions, CHMP2B mislocalization and accumulation in disease may be secondary to aberrant VPS4 regulation rather than the rare genetic mutations that alter its primary structure and cause frontotemporal lobar degeneration [44].

Finally, studies on cultured neurons reveal that inhibition of lysosome-mediated clearance is essential for accumulation of autophagic intermediates [16]. It also leads to increased size and density of multivesicular bodies [58]. The defect that leads to GVB formation is not established, but our finding that GVBs colocalize more frequently with LAMP1 than 
lysosome marker CTSD suggest that diminished lysosome fusion efficiency is a candidate defect. A similar defect accompanies certain pathogenic CHMP2B mutations associated with frontotemporal dementia, which depress endosome-lysosome fusion by impairing the recruitment of proteins necessary for fusion to occur (e.g., Rab7 [59]). Stalling of the autophagic pathway at an intermediate stage may have contributed to the LC3 staining pattern observed in this study, since prolonged exposure to cytosolic Atg4 would be expected to release LC3 from the outer membrane, resulting in a diffuse rather than membrane-associated appearance typically found in model systems [60].

The strong colocalization of Cki $\delta$ with the GVB granule remains to be rationalized. Its presence suggests a selective enrichment relative to what might be expected from random bulk entrapment through lysosome delivery pathways. Casein kinase-1 family members, including Cki $\delta$, are established mediators of protein ubiquitination in cells through direct phosphorylation of E3 ligases or their recognition motifs [61-63]. Monoubiquitination is a well characterized signal for targeting plasma membrane-associated proteins for endocytosis $[64,65]$, and specific members of the casein kinase-1 family regulate this reaction [66]. It is conceivable that phosphorylated and ubiquitinated cargoes, along with the catalyst Cki $\delta$, end up together in GVBs through the endocytic pathway. The nature of this relationship and the role of Cki $\delta$ remains to be elucidated.

In summary, Ckiס-immunoreactive GVBs most strongly colocalize with markers of the late autophagic and endocytic compartments relative to lysosomal protease CTSD or early-stage autophagy markers LC3 and p62. We speculate that GVBs arise from an increased or aberrant flux through the endocytic pathway that is inefficiently cleared owing to a defect in lysosome fusion efficiency (Figure 1). As a result, flux is routed into the autophagic pathway, which accumulates amphisome-like intermediates in abnormally large sizes owing to the same lysosome-fusion defect combined with mTOR-mediated suppression of phagophore formation. This hypothesis rationalizes the presence of both CHMP2B and ubiquitin in the GVB granules without a need for increased autophagic flux. The upstream events that lead to this phenotype may offer clues to regulatory events associated with sporadic AD, and whether GVD has toxic or protective effects on neurons.

\section{Acknowledgments}

Authors thank Sandra L. Siedlak and Dr. Mark A. Smith, Case Western Reserve University Department of Pathology, for methacarn-fixed tissue specimens. This work was supported in part by a grant from the National Institute on Aging (AG14452, JK).

\section{References}

1. Simchowicz T. Histologische studien uber die senile dementz. Histological and Histopathological work on the cerebral cortex. 1911; 4:267-444.

2. Ball MJ. Topographic distribution of neurofibrillary tangles and granulovacuolar degeneration in hippocampal cortex of aging and demented patients. A quantitative study. Acta Neuropathol. 1978; 42:73-80. [PubMed: 654888]

3. Xu M, Shibayama H, Kobayashi H, Yamada K, Ishihara R, Zhao P, Takeuchi T, Yoshida K, Inagaki T, Nokura K. Granulovacuolar degeneration in the hippocampal cortex of aging and demented patients--a quantitative study. Acta Neuropathol. 1992; 85:1-9. [PubMed: 1285490]

4. Yamazaki Y, Takahashi T, Hiji M, Kurashige T, Izumi Y, Yamawaki T, Matsumoto M. Immunopositivity for ESCRT-III subunit CHMP2B in granulovacuolar degeneration of neurons in the Alzheimer's disease hippocampus. Neurosci Lett. 2010; 477:86-90. [PubMed: 20420883]

5. Lagalwar S, Berry RW, Binder LI. Relation of hippocampal phospho-SAPK/JNK granules in Alzheimer's disease and tauopathies to granulovacuolar degeneration bodies. Acta Neuropathol. 2007; 113:63-73. [PubMed: 17089132] 
6. Ball MJ, Lo P. Granulovacuolar degeneration in the ageing brain and in dementia. J Neuropathol Exp Neurol. 1977; 36:474-487. [PubMed: 870622]

7. Ball MJ. Neuronal loss, neurofibrillary tangles and granulovacuolar degeneration in the hippocampus with ageing and dementia. A quantitative study. Acta Neuropathol. 1977; 37:111-118. [PubMed: 848276]

8. Ghoshal N, Garcia-Sierra F, Wuu J, Leurgans S, Bennett DA, Berry RW, Binder LI. Tau conformational changes correspond to impairments of episodic memory in mild cognitive impairment and Alzheimer's disease. Exp Neurol. 2002; 177:475-493. [PubMed: 12429193]

9. Okamoto K, Hirai S, Iizuka T, Yanagisawa T, Watanabe M. Reexamination of granulovacuolar degeneration. Acta Neuropathol. 1991; 82:340-345. [PubMed: 1722607]

10. Arstila AU, Trump BF. Studies on cellular autophagocytosis. The formation of autophagic vacuoles in the liver after glucagon administration. Am J Pathol. 1968; 53:687-733. [PubMed: 4300890]

11. Kabeya Y, Mizushima N, Ueno T, Yamamoto A, Kirisako T, Noda T, Kominami E, Ohsumi Y, Yoshimori T. LC3, a mammalian homologue of yeast Apg8p, is localized in autophagosome membranes after processing. EMBO J. 2000; 19:5720-5728. [PubMed: 11060023]

12. Kabeya Y, Mizushima N, Yamamoto A, Oshitani-Okamoto S, Ohsumi Y, Yoshimori T. LC3, GABARAP and GATE16 localize to autophagosomal membrane depending on form-II formation. J Cell Sci. 2004; 117:2805-2812. [PubMed: 15169837]

13. Dunn WA Jr. Studies on the mechanisms of autophagy: maturation of the autophagic vacuole. J Cell Biol. 1990; 110:1935-1945. [PubMed: 2161853]

14. Eskelinen EL. Maturation of autophagic vacuoles in Mammalian cells. Autophagy. 2005; 1:1-10. [PubMed: 16874026]

15. Fader CM, Colombo MI. Autophagy and multivesicular bodies: two closely related partners. Cell Death Differ. 2009; 16:70-78. [PubMed: 19008921]

16. Boland B, Kumar A, Lee S, Platt FM, Wegiel J, Yu WH, Nixon RA. Autophagy induction and autophagosome clearance in neurons: relationship to autophagic pathology in Alzheimer's disease. J Neurosci. 2008; 28:6926-6937. [PubMed: 18596167]

17. Bjorkoy G, Lamark T, Brech A, Outzen H, Perander M, Overvatn A, Stenmark H, Johansen T. p62/SQSTM1 forms protein aggregates degraded by autophagy and has a protective effect on huntingtin-induced cell death. J Cell Biol. 2005; 171:603-614. [PubMed: 16286508]

18. Lübke, U.; Mercken, M.; Vandermeeren, M.; Ceuterick-de Groote, C.; Vanmechelen, E.; Martin, JJ.; Cras, P. Comparative study of granulovacuolar degeneration in neurodegenerative diseases. In: Nicolini, M., editor. Alzheimer's Disease and Related Disorders: Communications. Oxford: Pergamon Press; 1993. p. 149-150.

19. Holzer M, Gartner U, Stobe A, Hartig W, Gruschka H, Bruckner MK, Arendt T. Inverse association of Pin 1 and tau accumulation in Alzheimer's disease hippocampus. Acta Neuropathol. 2002; 104:471-481. [PubMed: 12410395]

20. Kannanayakal TJ, Tao H, Vandre DD, Kuret J. Casein kinase-1 isoforms differentially associate with neurofibrillary and granulovacuolar degeneration lesions. Acta Neuropathol. 2006; 111:413421. [PubMed: 16557393]

21. Bondareff W, Wischik CM, Novak M, Roth M. Sequestration of tau by granulovacuolar degeneration in Alzheimer's disease. Am J Pathol. 1991; 139:641-647. [PubMed: 1909492]

22. Dickson DW, Ksiezak-Reding H, Davies P, Yen SH. A monoclonal antibody that recognizes a phosphorylated epitope in Alzheimer neurofibrillary tangles, neurofilaments and tau proteins immunostains granulovacuolar degeneration. Acta Neuropathol. 1987; 73:254-258. [PubMed: 2441560]

23. Ikegami K, Kimura T, Katsuragi S, Ono T, Yamamoto H, Miyamoto E, Miyakawa T. Immunohistochemical examination of phosphorylated tau in granulovacuolar degeneration granules. Psychiatry Clin Neurosci. 1996; 50:137-140. [PubMed: 9201760]

24. Mena R, Robitaille Y, Cuello AC. New patterns of intraneuronal accumulation of the microtubular binding domain of tau in granulovacuolar degeneration. J Geriatr Psychiatry Neurol. 1992; 5:132141. [PubMed: 1323297] 
25. Ghoshal N, Smiley JF, DeMaggio AJ, Hoekstra MF, Cochran EJ, Binder LI, Kuret J. A new molecular link between the fibrillar and granulovacuolar lesions of Alzheimer's disease. Am J Pathol. 1999; 155:1163-1172. [PubMed: 10514399]

26. Mirra SS, Heyman A, McKeel D, Sumi SM, Crain BJ, Brownlee LM, Vogel FS, Hughes JP, van Belle G, Berg L. The Consortium to Establish a Registry for Alzheimer's Disease (CERAD). Part II. Standardization of the neuropathologic assessment of Alzheimer's disease. Neurology. 1991; 41:479-486. [PubMed: 2011243]

27. Braak H, Braak E. Neuropathological stageing of Alzheimer-related changes. Acta Neuropathol. 1991; 82:239-259. [PubMed: 1759558]

28. Evers P, Uylings HB, Suurmeijer AJ. Antigen retrieval in formaldehyde-fixed human brain tissue. Methods. 1998; 15:133-140. [PubMed: 9654460]

29. Schnell SA, Staines WA, Wessendorf MW. Reduction of lipofuscin-like autofluorescence in fluorescently labeled tissue. Journal of Histochemistry and Cytochemistry. 1999; 47:719-730. [PubMed: 10330448]

30. Newcombe RG. Improved confidence intervals for the difference between binomial proportions based on paired data. Stat Med. 1998; 17:2635-2650. [PubMed: 9839354]

31. Mizushima N. Methods for monitoring autophagy. Int J Biochem Cell Biol. 2004; 36:2491-2502. [PubMed: 15325587]

32. Kimura S, Noda T, Yoshimori T. Dissection of the autophagosome maturation process by a novel reporter protein, tandem fluorescent-tagged LC3. Autophagy. 2007; 3:452-460. [PubMed: 17534139]

33. Ma JF, Huang Y, Chen SD, Halliday G. Immunohistochemical evidence for macroautophagy in neurons and endothelial cells in Alzheimer's disease. Neuropathol Appl Neurobiol. 2010; 36:312319. [PubMed: 20102518]

34. Kuusisto E, Salminen A, Alafuzoff I. Ubiquitin-binding protein p62 is present in neuronal and glial inclusions in human tauopathies and synucleinopathies. Neuroreport. 2001; 12:2085-2090. [PubMed: 11447312]

35. Kuusisto E, Salminen A, Alafuzoff I. Early accumulation of p62 in neurofibrillary tangles in Alzheimer's disease: possible role in tangle formation. Neuropathol Appl Neurobiol. 2002; 28:228-237. [PubMed: 12060347]

36. Kuusisto E, Kauppinen T, Alafuzoff I. Use of p62/SQSTM1 antibodies for neuropathological diagnosis. Neuropathol Appl Neurobiol. 2008; 34:169-180. [PubMed: 17961133]

37. Pankiv S, Clausen TH, Lamark T, Brech A, Bruun JA, Outzen H, Overvatn A, Bjorkoy G, Johansen T. p62/SQSTM1 binds directly to Atg8/LC3 to facilitate degradation of ubiquitinated protein aggregates by autophagy. J Biol Chem. 2007; 282:24131-24145. [PubMed: 17580304]

38. Chen JW, Murphy TL, Willingham MC, Pastan I, August JT. Identification of two lysosomal membrane glycoproteins. J Cell Biol. 1985; 101:85-95. [PubMed: 2409098]

39. Lewis V, Green SA, Marsh M, Vihko P, Helenius A, Mellman I. Glycoproteins of the lysosomal membrane. J Cell Biol. 1985; 100:1839-1847. [PubMed: 3922993]

40. Amano T, Nakanishi H, Kondo T, Tanaka T, Oka M, Yamamoto K. Age-related changes in cellular localization and enzymatic activities of cathepsins B, L and D in the rat trigeminal ganglion neuron. Mech Ageing Dev. 1995; 83:133-141. [PubMed: 8583832]

41. Casciola-Rosen LA, Renfrew CA, Hubbard AL. Lumenal labeling of rat hepatocyte endocytic compartments. Distribution of several acid hydrolases and membrane receptors. J Biol Chem. 1992; 267:11856-11864. [PubMed: 1318303]

42. Runquist EA, Havel RJ. Acid hydrolases in early and late endosome fractions from rat liver. J Biol Chem. 1991; 266:22557-22563. [PubMed: 1658000]

43. Raiborg C, Stenmark H. The ESCRT machinery in endosomal sorting of ubiquitylated membrane proteins. Nature. 2009; 458:445-452. [PubMed: 19325624]

44. Urwin H, Ghazi-Noori S, Collinge J, Isaacs A. The role of CHMP2B in frontotemporal dementia. Biochem Soc Trans. 2009; 37:208-212. [PubMed: 19143633]

45. Wollert T, Wunder C, Lippincott-Schwartz J, Hurley JH. Membrane scission by the ESCRT-III complex. Nature. 2009; 458:172-177. [PubMed: 19234443] 
46. Fornai F, Lenzi P, Gesi M, Soldani P, Ferrucci M, Lazzeri G, Capobianco L, Battaglia G, De Blasi A, Nicoletti F, Paparelli A. Methamphetamine produces neuronal inclusions in the nigrostriatal system and in PC12 cells. J Neurochem. 2004; 88:114-123. [PubMed: 14675155]

47. Lazzeri G, Lenzi P, Busceti CL, Ferrucci M, Falleni A, Bruno V, Paparelli A, Fornai F. Mechanisms involved in the formation of dopamine-induced intracellular bodies within striatal neurons. J Neurochem. 2007; 101:1414-1427. [PubMed: 17286589]

48. Diaz-Troya S, Perez-Perez ME, Florencio FJ, Crespo JL. The role of TOR in autophagy regulation from yeast to plants and mammals. Autophagy. 2008; 4:851-865. [PubMed: 18670193]

49. Li X, Alafuzoff I, Soininen H, Winblad B, Pei JJ. Levels of mTOR and its downstream targets 4EBP1, eEF2, and eEF2 kinase in relationships with tau in Alzheimer's disease brain. FEBS J. 2005; 272:4211-4220. [PubMed: 16098202]

50. Soliman GA, Acosta-Jaquez HA, Dunlop EA, Ekim B, Maj NE, Tee AR, Fingar DC. mTOR Ser-2481 autophosphorylation monitors mTORC-specific catalytic activity and clarifies rapamycin mechanism of action. J Biol Chem. 2010; 285:7866-7879. [PubMed: 20022946]

51. Hirano A, Dembitzer HM, Kurland LT, Zimmerman HM. The fine structure of some intraganglionic alterations. Neurofibrillary tangles, granulovacuolar bodies and "rod-like" structures as seen in Guam amyotrophic lateral sclerosis and parkinsonism-dementia complex. J Neuropathol Exp Neurol. 1968; 27:167-182. [PubMed: 5646193]

52. Kadokura A, Yamazaki T, Kakuda S, Makioka K, Lemere CA, Fujita Y, Takatama M, Okamoto K. Phosphorylation-dependent TDP-43 antibody detects intraneuronal dot-like structures showing morphological characters of granulovacuolar degeneration. Neurosci Lett. 2009; 463:87-92. [PubMed: 19539703]

53. Komatsu M, Waguri S, Koike M, Sou YS, Ueno T, Hara T, Mizushima N, Iwata J, Ezaki J, Murata S, Hamazaki J, Nishito Y, Iemura S, Natsume T, Yanagawa T, Uwayama J, Warabi E, Yoshida H, Ishii T, Kobayashi A, Yamamoto M, Yue Z, Uchiyama Y, Kominami E, Tanaka K. Homeostatic levels of p62 control cytoplasmic inclusion body formation in autophagy-deficient mice. Cell. 2007; 131:1149-1163. [PubMed: 18083104]

54. Tomlinson BE, Kitchener D. Granulovacuolar degeneration of hippocampal pyramidal cells. J Pathol. 1972; 106:165-185. [PubMed: 4114032]

55. Nixon RA. Endosome function and dysfunction in Alzheimer's disease and other neurodegenerative diseases. Neurobiol Aging. 2005; 26:373-382. [PubMed: 15639316]

56. Wollert T, Hurley JH. Molecular mechanism of multivesicular body biogenesis by ESCRT complexes. Nature. 2010; 464:864-869. [PubMed: 20305637]

57. Lata S, Schoehn G, Jain A, Pires R, Piehler J, Gottlinger HG, Weissenhorn W. Helical structures of ESCRT-III are disassembled by VPS4. Science. 2008; 321:1354-1357. [PubMed: 18687924]

58. Vanlandingham PA, Ceresa BP. Rab7 regulates late endocytic trafficking downstream of multivesicular body biogenesis and cargo sequestration. J Biol Chem. 2009; 284:12110-12124. [PubMed: 19265192]

59. Urwin H, Authier A, Nielsen JE, Metcalf D, Powell C, Froud K, Malcolm DS, Holm I, Johannsen P, Brown J, Fisher EM, van der Zee J, Bruyland M, Van Broeckhoven C, Collinge J, Brandner S, Futter C, Isaacs AM. Disruption of endocytic trafficking in frontotemporal dementia with CHMP2B mutations. Hum Mol Genet. 2010; 19:2228-2238. [PubMed: 20223751]

60. Kirisako T, Ichimura Y, Okada H, Kabeya Y, Mizushima N, Yoshimori T, Ohsumi M, Takao T, Noda T, Ohsumi Y. The reversible modification regulates the membrane-binding state of Apg8/ Aut7 essential for autophagy and the cytoplasm to vacuole targeting pathway. J Cell Biol. 2000; 151:263-275. [PubMed: 11038174]

61. Galletti M, Riccardo S, Parisi F, Lora C, Saqcena MK, Rivas L, Wong B, Serra A, Serras F, Grifoni D, Pelicci P, Jiang J, Bellosta P. Identification of domains responsible for ubiquitindependent degradation of dMyc by glycogen synthase kinase $3 \beta$ and casein kinase 1 kinases. Mol Cell Biol. 2009; 29:3424-3434. [PubMed: 19364825]

62. Winter M, Milne D, Dias S, Kulikov R, Knippschild U, Blattner C, Meek D. Protein kinase CK1 $\delta$ phosphorylates key sites in the acidic domain of murine double-minute clone 2 protein (MDM2) that regulate p53 turnover. Biochemistry. 2004; 43:16356-16364. [PubMed: 15610030] 
63. Zhao B, Li L, Tumaneng K, Wang CY, Guan KL. A coordinated phosphorylation by Lats and CK1 regulates YAP stability through $\mathrm{SCF}^{\beta-\mathrm{TRCP}}$. Genes Dev. 2010; 24:72-85. [PubMed: 20048001]

64. Katzmann DJ, Odorizzi G, Emr SD. Receptor downregulation and multivesicular-body sorting. Nat Rev Mol Cell Biol. 2002; 3:893-905. [PubMed: 12461556]

65. Raiborg C, Rusten TE, Stenmark H. Protein sorting into multivesicular endosomes. Curr Opin Cell Biol. 2003; 15:446-455. [PubMed: 12892785]

66. Marchal C, Haguenauer-Tsapis R, Urban-Grimal D. Casein kinase I-dependent phosphorylation within a PEST sequence and ubiquitination at nearby lysines signal endocytosis of yeast uracil permease. J Biol Chem. 2000; 275:23608-23614. [PubMed: 10811641]

67. Berglund L, Bjorling E, Oksvold P, Fagerberg L, Asplund A, Szigyarto CA, Persson A, Ottosson J, Wernerus H, Nilsson P, Lundberg E, Sivertsson A, Navani S, Wester K, Kampf C, Hober S, Ponten F, Uhlen M. A genecentric Human Protein Atlas for expression profiles based on antibodies. Mol Cell Proteomics. 2008; 7:2019-2027. [PubMed: 18669619]

68. Bedford L, Hay D, Devoy A, Paine S, Powe DG, Seth R, Gray T, Topham I, Fone K, Rezvani N, Mee M, Soane T, Layfield R, Sheppard PW, Ebendal T, Usoskin D, Lowe J, Mayer RJ. Depletion of $26 \mathrm{~S}$ proteasomes in mouse brain neurons causes neurodegeneration and Lewy-like inclusions resembling human pale bodies. J Neurosci. 2008; 28:8189-8198. [PubMed: 18701681]

69. Byun JY, Yoon CH, An S, Park IC, Kang CM, Kim MJ, Lee SJ. The Rac1/MKK7/JNK pathway signals upregulation of Atg5 and subsequent autophagic cell death in response to oncogenic Ras. Carcinogenesis. 2009; 30:1880-1888. [PubMed: 19783847]

70. Kovacs GG, Gelpi E, Strobel T, Ricken G, Nyengaard JR, Bernheimer H, Budka H. Involvement of the endosomal-lysosomal system correlates with regional pathology in Creutzfeldt-Jakob disease. J Neuropathol Exp Neurol. 2007; 66:628-636. [PubMed: 17620988] 


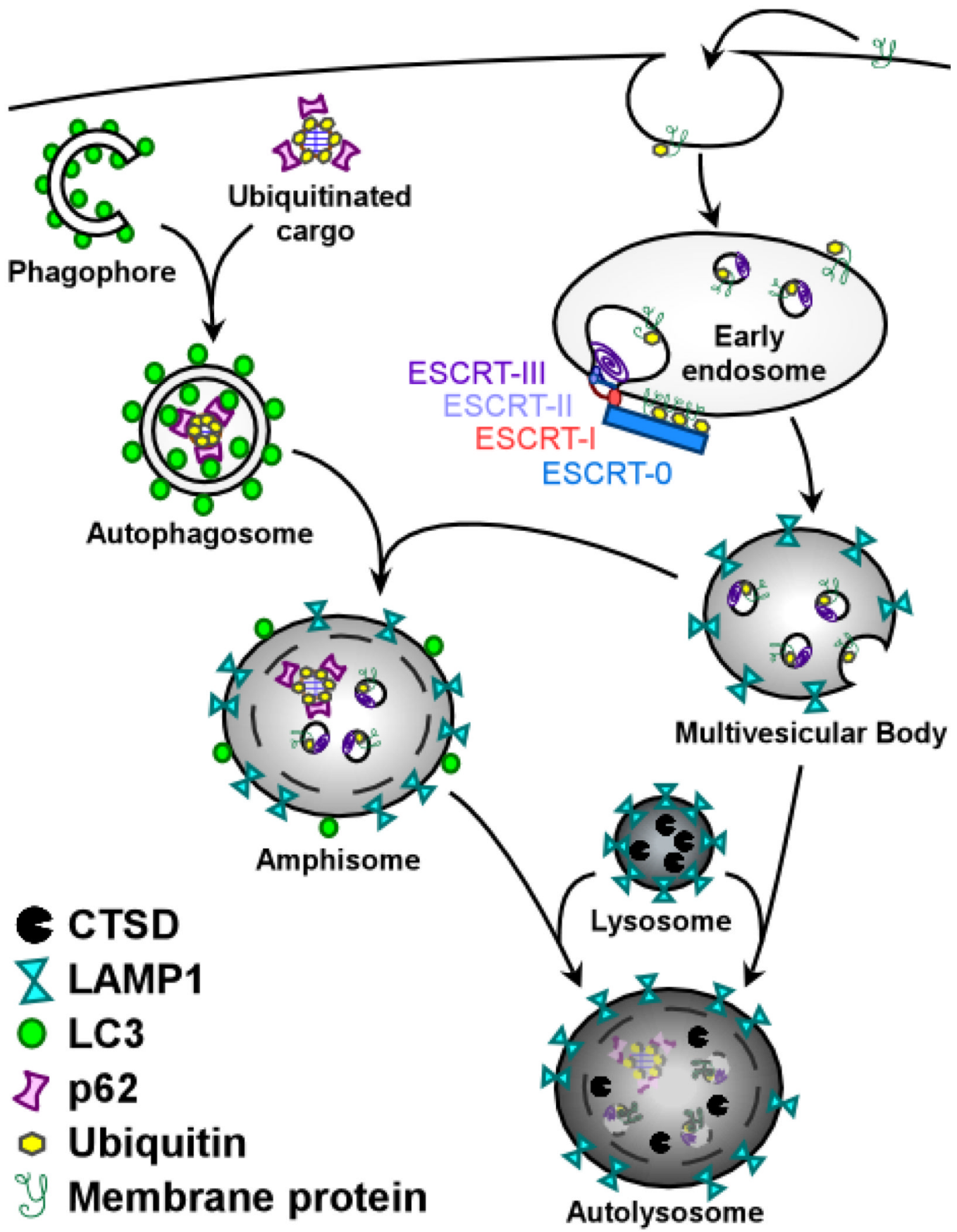

Figure 1. Convergence of the autophagic and endocytic pathways destined for lysosomemediated degradation

In the autophagy pathway, p62-bound ubiquitinated organelles and cytosolic proteins targeted for degradation are engulfed by the phagophore, a double-layered membrane decorated by LC3-II, creating the autophagosome. In the endocytic pathway, internalized membrane proteins destined for lysosomal degradation are sorted into intraluminal vesicles of the MVB by sequential activity of ESCRTs 0, I, II, and III. CHMP2B is part of the ESCRT-III complex, which as a whole is specifically required for the abscission activity in the final stages of intraluminal vesicle formation. Mature MVBs fuse either with the autophagosome to form the amphisome or directly with the lysosome. Upon fusion with the 
MVB, the amphisome acquires vacuolar ATPases, which acidify the lumen, and lysosomal membrane proteins. Fusion of the amphisome with the lysosome, which donates degradative hydrolases, creates the autolysosome where complete degradation of the sequestered material occurs. See text for details. 


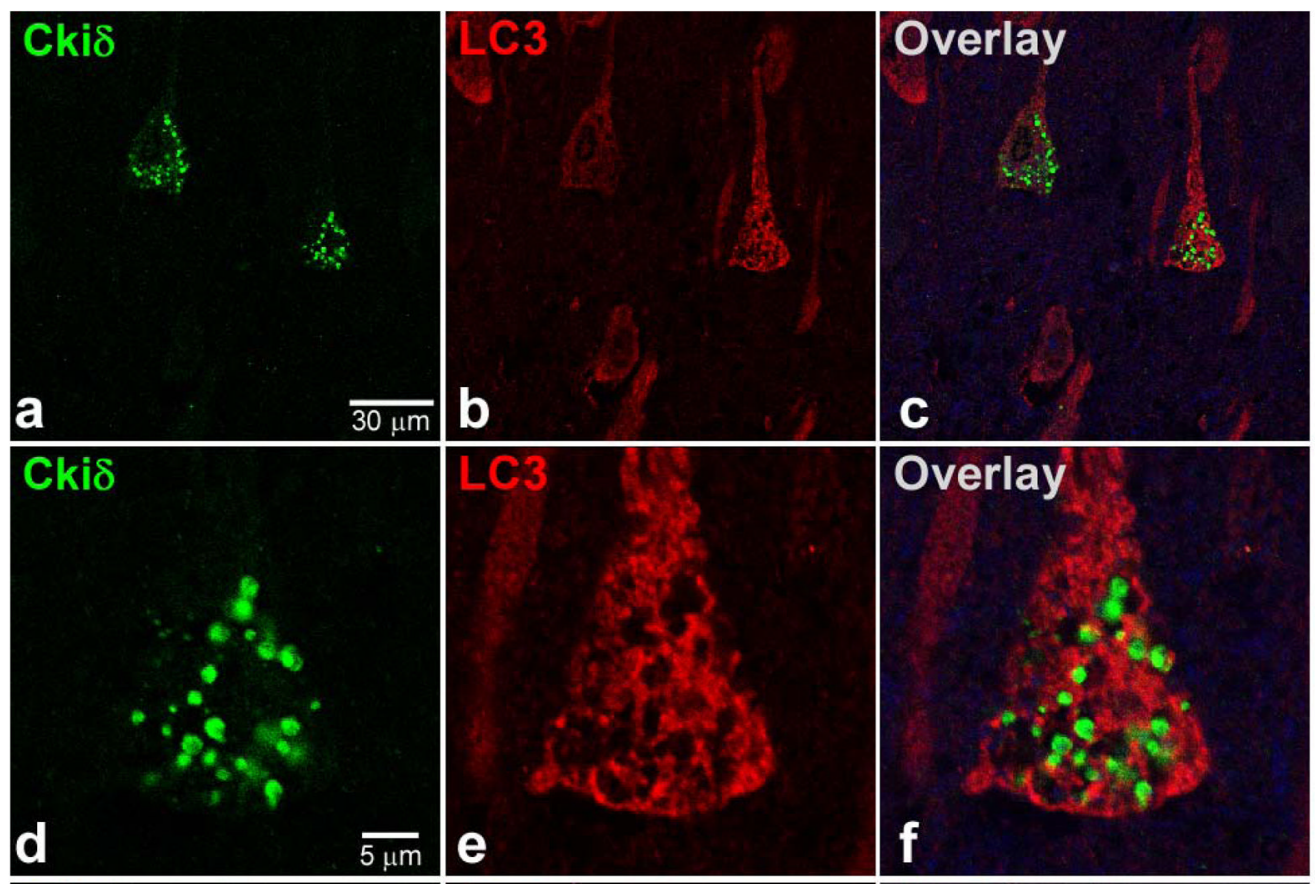

Zoom

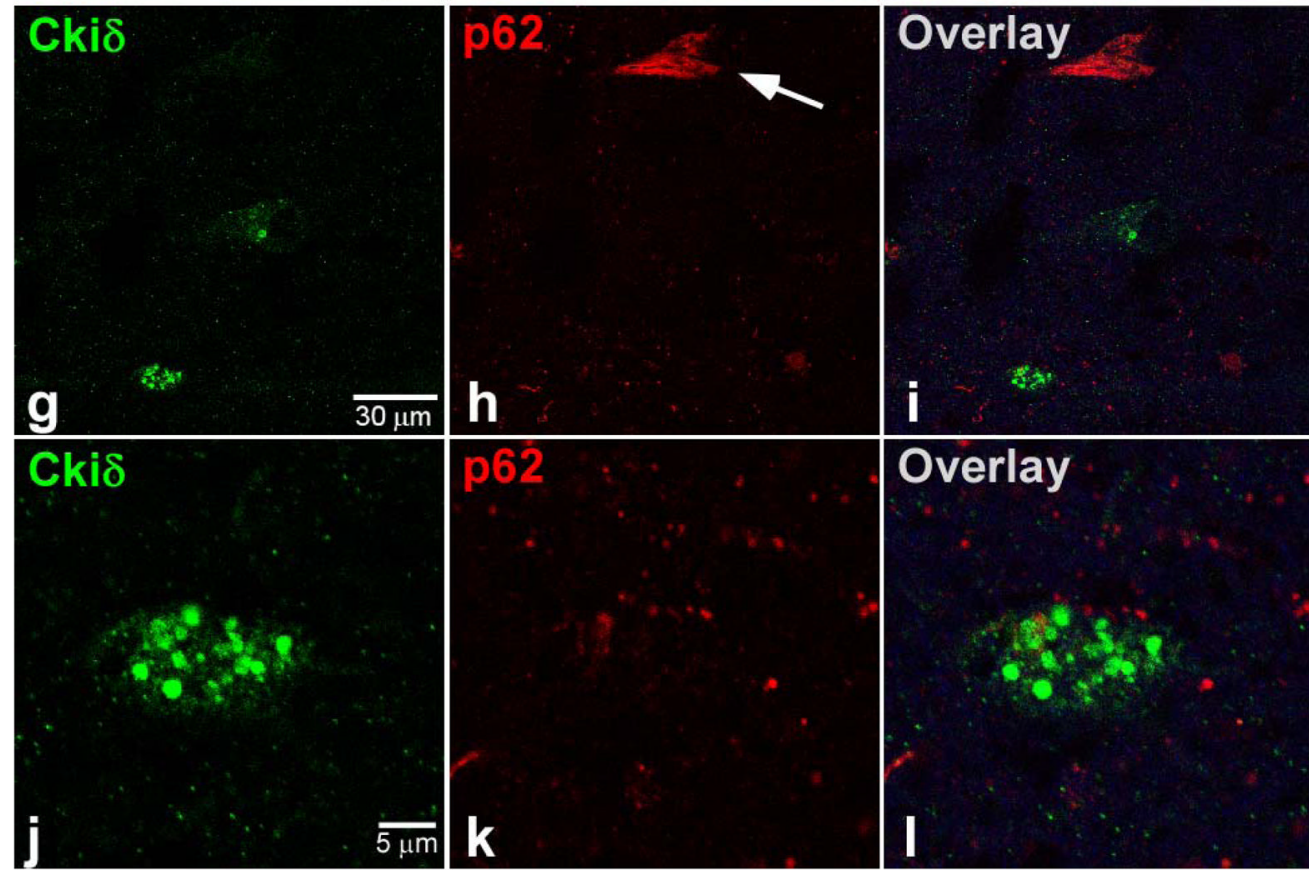

$1 \mathrm{X}$

Figure 2. Colocalization of GVBs with early-stage autophagy markers

Double-label confocal images (1x digital zoom, a-c, $\mathbf{g}-\mathbf{i} ; 4 \mathrm{x}$ digital zoom, $\mathbf{d}-\mathbf{f}, \mathbf{j}-\mathbf{l}$ ) of hippocampal sections stained with anti-Cki $\delta$ antibody (green channel; $\mathbf{a}, \mathbf{d}, \mathbf{g}, \mathbf{j}$ ), which labels the GVB granule, and antibodies against LC3 (red channel; b, e) and p62 (red channel; $\mathbf{h}, \mathbf{k})$. Image overlays $(\mathbf{c}, \mathbf{f}, \mathbf{i}, \mathbf{l})$ highlight pixel overlap between Cki $\delta$ and marker immunoreactivity in yellow. GVBs colocalized weakly with either LC3 or p62. In contrast, p62 colocalized with neurofibrillary tangles (h, arrow). Scale bars apply to each row. 


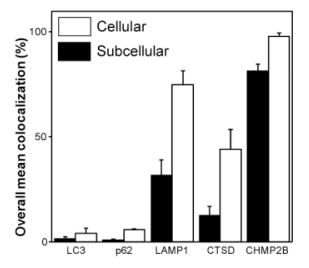

Figure 3. Quantification of GVB colocalization

Bars correspond to the overall mean percent colocalization of LC3, p62, LAMP1, CTSD, and CHMP2B immunoreactivity with GVBs \pm SEM ( $n=5$ cases). Direct colocalization was defined as encircling and granular patterns. Statistical analysis of these data is summarized in Tables 3 and 4. 


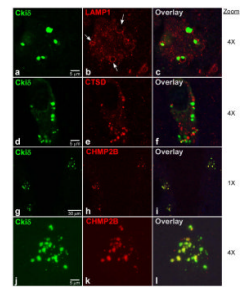

Figure 4. Colocalization of GVBs with late-stage autophagic and endocytic markers Double-label confocal images (4x digital zoom, a-f, $\mathbf{j}-\mathbf{l}$; 1x digital zoom, $\mathbf{g}-\mathbf{i}$ ) of hippocampal sections stained with anti- Cki $\delta$ antibody (green channel) and antibodies against LAMP1, CTSD, and CHMP2B (red channel). High magnification panels $\mathbf{j}-\mathbf{l}$ are three dimensional reconstructions, each composed of a stack of 25 optical slices acquired at

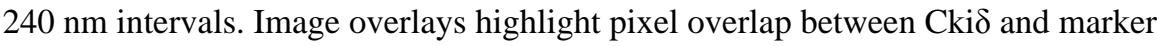
immunoreactivity in yellow. GVBs colocalized strongly with LAMP1, which stained the encircling GVB membrane (b, arrows), weakly with CTSD, which labeled a population of vesicles distinct from GVBs, and strongly with $\mathrm{CHMP} 2 \mathrm{~B}$, which co-labeled the core granule. Scale bars apply to each row. 
